\title{
The radical need for Semiotics in IS research and practice - Why the urgency?
}

\author{
Ângela Lacerda Nobre - Escola Superior de Ciências Empresariais do Instituto Politécnico de Setúbal \\ ESCE-IPS angela.nobre@esce.ips.pt
}

\begin{abstract}
There is a radical need for semiotics in information systems research and practice. Is semiotic theory a well developed knowledge area, offering insights that cross all epistemic positions, from positivism to realism, from structuralism to post-structuralism, and able to study all areas and dimensions of society? Yes. Has computing science research explored such links? Yes. And is this body of knowledge available within educational and training curricula? Does it reach actual practice? Has it been able to affect business strategies, operations and end results? Have managers and intellectual leaders been aware of the power and unexplored potential of semiotics? No. Why? Who is to blame? What can be done about this? And why the urgency?

There are no direct answers to these questions. Yet it is possible to identify critical features of current contexts that open the way to a greater awareness towards the vast potential of semiotics. First, the context of transition from industrial to post-industrial society; second, the tensions between modern and post-modern forms of rationality; third, the role of knowledge, at individual, business and societal levels; fourth, how semiotic developments lie largely unexplored; fifth, how mainstream management thinking fails to acknowledge the links between formal and informal (prefiguring) processes; sixth, how business process modelling and other approaches remain closed onto themselves, in a modernist and reductive logic; seventh, how globalisation reflects an increase in efficiency and also unprecedented complexity; eight, the importance of the links between knowledge and power, and between academia, industry and political spheres; ninth, the mainstream management's prevalence of the command and control paradigm of the industrial era; tenth, how philosophical developments, semiotics in particular, has the potential to address all these dimensions and spheres of action that characterise current business and organisational challenges.
\end{abstract}

The answers to these challenges will come from an improved background given to managers and practitioners; from an educational offer that enables semiotics to have large returns on investment and spill-over, catalyst and multiplying effects within and across organisational borders; from scientific knowledge communities, publishing institutions and academic departments that promote and profit from the internal use of semiotic theories and methodologies; and from political, research and practitioners actions that unleash the potential of semiotics in terms of how it may enable the full manifestation of reality's possibilities, that is, the exploration and even expansion of actual potential at individual, organisation and societal levels.

Key-words: semiotics, post-industrial society, transformational change, innovation, semiotic learning.

\section{Introduction}

Ronald Stamper (1973), the founder of the Organisational Semiotics knowledge area radically discards common terminology in order to introduce new perspectives:

"Let us begin by discarding... "information", "meaning", "knowledge" and how they "flow" as we "communicate" them - as though these were all simple, primitive notions we all understand.... Instead, let us use the notion of a sign as a primitive concept." (Stamper, 2000). 
This comment is relevant in terms of the way it shifts the attention towards solid theoretical and epistemological grounding of scientific knowledge production within management and information sciences. This applies also to the way that change is understood.

There are many sides to the issue of the need for change. Change in management science and in organisational practice, change in society in order to take full profit from the benefits of technology and of globalisation, and change in the production of scientific knowledge itself. The so called "crisis in science" is one way to highlight the transition that is taking place in the change from industrial to postindustrial society and from modernity to post-modernity.

Information and communication technology (ICT) in general and Information Systems (IS) in particular are at the epicentre of such changes and the reason is twofold. First, the technological revolution is the tip of the iceberg of the wide spread changes that have occurred at social, cultural, economical and political levels across all spheres of society. This technology impact is simultaneously a result and a producer and enabler of further changes. Second, ICT and IS are grounded in the broad area of computing science. This scientific area is less than one hundred years old. This implies that it developed its autonomy through drawing key insights from several knowledge areas, from engineering to management.

However, conversely to what has happened to those areas, there has been a thorough effort to go deeper in terms of the theoretical and philosophical grounding of its theories. The importance of systems theory and of how it developed from the insights proposed by structuralism, which itself had drawn its rationale from Saussure's language analysis, is an example of such efforts. Yet, these efforts have not had a widely disseminated impact. That is, there are impressive examples of philosophically based computing science research but the impact that such work has had in terms of affecting current practices in terms of ICT and IS research is marginal and peripheral.

This conclusion is dramatic. It implies that there is a vast amount of sophisticated knowledge production that lies largely unexplored. And this knowledge is critical not only in terms of what it can do for organisational and business effectiveness but also in terms of the impact it may have in society as a whole.

The problems of coordination, of creating rules and routines and, at the same time, of remaining flexible and becoming innovative, describe the challenges posed both to organisations and to societies. Global society is an ecosystem, and the same can be said of any business.

To make crystal clear the issue that is at hand, the double argument may be summarised as follows. On one hand, both business and organisations as well as society as a whole currently undergo severe structural changes related to the transitions that are taking place in contemporary times, changes that are felt as market turbulence and increased competitiveness, as economic and financial crises, as war conflicts and ecological dramas, at personal level and in terms of public health issues. These changes are directly and indirectly related to the impact technology has on society - and social change also presses for further technological development. On the other hand, the knowledge that has been accumulated lies largely unexplored. Computing science and the philosophical grounding of its theory 
building offer a huge potential that is far from reaching mainstream thinking and dominant practice at business and organisational levels. Does this means that computing science is a panacea for the resolution of all society's problems? Or, conversely, that IS do have a real impact on how businesses and organisations are run and that ICT in general transversely affects all areas of society's life in a pervasive way?

On one hand we have identified the problems and on the other hand we have acknowledged potential solutions or sources for further solutions. That is, computing science research that has been developed in the last five decades addresses the philosophical interpretations of organisational reality, bringing novelty and addressing its complexity. And the theoretical developments from one hundred years ago offer rich insights that are still not fully explored.

This argument is valid in relation to a vast array of philosophical sources, from language and action philosophy to post-modern research. Yet it is semiotics theory that offers one of the most powerful and still little understood conceptual frameworks to interpret current reality. As argues Stamper, we are still scratching the surface of what semiotics has to offer.

"Far more important than efficiency are such information systems properties as openness, honesty, trust, fairness, justice and accountability, responsibility and truthfulness. These are not even registered by our current methods." (Stamper, 2000).

\section{Post-industrial society and the role of organisational learning in KIO}

The context of the post-industrial society implies that knowledge has acquired a central position regarding the organisation of economic activity. The pace of change of our societies, the technological evolution, the globalisation of markets, the centrality of knowledge and the 'networking logic' (Castells, 1998) lead organisations to value learning as an ongoing process. This learning process, in turn, needs to be understood, valued and mastered.

The improvement of learning processes at organisational level needs to be facilitated in order to enable this learning to be continuous and, simultaneously, effective. This is particularly important for 'knowledge-intensive organisations' (KIO) (e.g. Drucker, 1969, 1999, Pursuer, Cabana, 1998, Alvesson, 1995, Ostwald, 1996, Rosendaal, 2006). These can be described as organisations where knowledge is valued as their main asset and central competence, and which organise themselves around their core knowledge processes.

Organisations in this knowledge economy context organise themselves around their core knowledge processes, thus becoming knowledge-intensive organisations. In turn, the need to understand, to acknowledge and to respond to the dynamic and collective nature of knowledge creation and sharing leads organisations to value their learning processes. This implies that organisational learning becomes a central concern of knowledge-intensive organisations.

Within this background there is a central problem that stands out, related with the nature of knowledge and learning as dynamic processes. Different authors from diverse fields of study have addressed the tension between formal and informal knowledge (e.g. Stamper, 2000, Marsick, Watkins, 2001,) and 
between tacit and explicit knowledge (Polanyi, 1958). This informal and tacit knowledge is critical for knowledge-intensive organisations as it not imitable by competitors, thus being a source of sustainable competitive advantages (e.g. Quinn, 1992, Pursuer, Cabana, 1998, Rosendaal, 2006).

The basic rationale is that (i) informal and tacit knowledge precedes and gives rise to formal and explicit knowledge, and (ii) that informal and tacit knowledge is shared through the participation in actual practices. This implies that organisational interventions that nurture and empower (and thus facilitate) learning are critical. This facilitation enables the strengthening of organisational social practices that support knowledge creation and sharing.

According to Child and Heavens (2001), there are several authors that work at the margin and periphery of dominant cognitivist thinking and that are increasingly making their presence noticed in the fields of organisational learning so that we could envision a 'social turn' in organisation theory. Yanow (2001) stresses the technical-social divide within organisational learning literature, the technical side focusing on measurement and the social side focusing on interventions that "facilitate social processes". This author agrees that her own work belongs to the social tradition, interpreting learning as a "social act of sensemaking", while the technical side treats learning as "technical processing of information" (Yanow, 2001). On this researcher's opinion, these differences represent different philosophical presuppositions regarding the nature of reality and its knowability and cannot be easily accommodated within the same study or by the same researcher.

Both management theories, which focus on achieving results, and organisation theories, that focus on the logic and structure, i.e. the organisation, that is behind those results, are gradually showing a new interest in the social aspects of human interaction. This is critically relevant for knowledge-intensive organisations or network, knowledge-driven or knowledge-based organisations. "Innovation, learning and knowledge leverage are crucial for the competitive edge of knowledge-intensive firms" (Ojanen, Hallikas, 2009).

Knowledge, within this context, is interpreted in a broad form incorporating technical, formal and explicit elements as well as tacit (Polanyi, 1958), cultural and social aspects (Yanow, 2000). When studying collective activity, behaviour and explicit knowledge are the main visible elements. However, behind observable behaviour we have meanings and motives that direct and determine people's actions and decision-making processes. These meanings and motives, in turn, are the product of ongoing social practices, of the participation in social relations, and of the influence of social contexts.

The quality of interpersonal interaction is critical for organisational learning and development (Bokeno, 2009). According to the perspective adopted by the present research, organisational learning has to be understood and studied in a way that is consistent with this background of key social concepts. As Yanow (2001) stresses, learning is a "social act of sensemaking". 


\section{Transformational change, innovation and semiotic learning}

Organisational learning plays an active role in every organisation as it is, in itself, a condition for survival. Organisational learning already exists, spontaneously and implicitly.

"The learning organisation is an invention, not a discovery, a proposal, not an observation. Having said that, it is clearly one that manages its own learning process to its advantage. The organisational learning process can, and indeed arguably must, exist whether it is known and managed, and to good effect or not - just as everyone has a state of health, what varies is whether it is good or bad, known or unknown." (Burgoyne, 1995).

As Burgoyne jokingly argues, organisational learning, like the health state of individuals, "is always there". However, its quality and degree of consciousness in relation to its actual state may vary. Consequently, raising awareness towards this actual state is an important step in the process of improving organisational learning.

In general terms, the recognition that learning is pervasive, ubiquitous and unavoidable in all human contexts helps to address the ambit of the discipline of "organisational learning".

"It is almost a natural impulse to tell others what we know. Erik Erickson, the great developmental psychologist, said that we are, by nature, 'a teaching species'." (Dixon, 2000).

To learn is generally understood as the ability to gain knowledge or skill by studying, from experience, from being taught, or from other forms of instruction. This general definition hides the inherent intricacies of learning processes. The concept of learning is highly complex and culturally marked. The social and participative nature of learning has been widely recognised (e.g., Summerfield, Kingsnorth, 2009). As individuals, we often recognise as learning only external contributions to our knowledge, what someone has taught us. We seldom value the importance of our own experiences, attitudes, efforts, values, memories and previous knowledge that apparently have a far greater importance to the effectiveness of the learning process itself. This is the argument of experientially based perspectives on learning (e.g. Dewey, 1938, Gherardi, 2006).

Our own attitudes and mindset are deeply linked and intertwined with our social environment, again, culturally marked. Living in a society that shows prevalence for 'individuality' we seldom incorporate the lessons from social and philosophy theory into everyday organisational practices.

The critical role of networks and its relation to organisational learning is fundamental to the understanding of organisational dynamics (Hallikas, et al, 2009). The social perspective is highly attentive to organisational communities (Checkland, 1999) as the setting of social practices and of social discourse. For Weick (1995), cognition is "socially mediated sensemaking". And, for Morgan (1997), the life of an organisation is embodied in its community. This community dimension is critical to the development of the Semiotic Learning framework. Social philosophy theory, namely Halliday's (1978) social semiotics, Peirce's (1931) pragmatism and Heidegger's (1962) ontology, are particularly relevant to the study of organisational social reality.

Semiotic Learning is a conceptual framework and a practical method to facilitate learning in knowledge-intensive organisations. Semiotic Learning thus concerns the process of improving organisational learning. It explores a social approach to organisational learning, based on socio- 
philosophy contributions. This research is directed at the study of the relational aspects and the community-level contexts that indirectly affect organisational formal results. This is important because ongoing organisational social practices predetermine explicit outcomes. The relevance of such an approach is that it enables addressing the social dimensions that implicitly condition organisational life. The social aspects of organisational learning are crucial and these aspects are often neglected in organisational theory and practice.

The proposed approach does not substitute other organisational development approaches such as reengineering or cognitivist organisational learning interventions. Conversely, it stresses the crucial role of the implicit, informal and tacit aspects of learning.

Community building and knowledge sharing initiatives need specific and continuous support at organisational level. Semiotic Learning creates and nurtures such collaborative environment through ongoing small group interventions. Direct and explicit efforts to sustain a knowledge creating culture are crucial, in particular, for knowledge-intensive organisations, as was stressed above. At a fundamental level, these organisations must maintain a high level of awareness in relation to the strength of their community relations. And such is the task of Semiotic Learning.

The broad domains that are addressed may be grouped into (i) organisational learning and (ii) social philosophy. Within the organisational learning domain, it is important to position organisational learning within the context of the knowledge economy and of the epistemic shifts that have characterised the evolution of contemporary social sciences. The sub-domain of the knowledgeintensive organisations represents the impact that the new economy context has had at organisational level, forcing organisations to acknowledge the role of knowledge as their core asset and central competence. Within organisational learning theory, different approaches have emerged and it is important to revise their history and to identify the critical contributions from different schools of thought. The social tradition of organisational learning is particularly relevant as it is the one that addresses the social, cultural and contextual aspects that condition informal learning and tacit knowledge.

Social philosophy is an important domain when dealing with the informal and tacit aspects of learning because it offers a wide set of theories that support a strong theoretical fundamentation of collaborative and participatory forms of learning. Social semiotics, pragmatism and ontology are the main domains that support the Semiotic Learning framework. Semiotics is particularly important because it directly addresses the meaning-making processes that sustain knowledge creation and learning. Through linking individual learning to actual social practices and language use, social semiotics enables the study of how to improve informal learning and knowledge sharing at a tacit level. 


\section{Rationale}

The basic rationale of the present paper is the following. There are certain characteristics of current contexts that help us to identify key issues in relation to which semiotics has a word to say. Better, semiotics is a potential bridge, tool, lenses and mirror, enabling the exploration of the full possibilities of reality.

First, the importance of the context of contemporary society and the transition from industrial to postindustrial modes of production and consumption. Second, the creative tensions between modern and post-modern forms of rationality, being post-modernism an heterogeneous movement that radically questions the hegemony and the monolithic thinking of modernity, and does not offer an alternative, in terms of a ready-to-use rationality but rather calls attention to the limits of modernity and to the need to go beyond linear and cause-effect approaches, and to consider complexity, temporality and change. Third, the role of knowledge, at individual, business and societal levels, and its widely diverse epistemic interpretations, from a commodity view, where knowledge may be transacted, packaged and codified, to a socially embedded and embodied interpretation of knowledge. Fourth, how semiotics and other philosophical developments that have emerged in the last one hundred years lie largely unexplored because of the slow dissemination power among areas largely dominated by individualistic, technocentric and technocratic approaches to management sciences. Fifth, mainstream management thinking identifies crucial areas such as human resources or marketing and calls for the need to integrate business and technology, to align strategy and operations, to value business ethics and social responsibility and yet fail to understand the need to thoroughly grasp the relations between formal procedures, rules and norms and informal and spontaneous characteristics of organisational identity, because it is the informal that determines that which becomes formal, it is the creative potential and dynamisms of organisational action that conditions end results. Sixth, the vast developments achieved in the last few decades in areas ranging from business process modelling, workflow processes, knowledge systems, knowledge management, organisational learning or communities of practice theory illustrate the efforts from management and engineering sciences, but these fields have remained captive of the modernist logic of differentiation and autonomy of knowledge areas, implying that the more each of these areas advances, becomes more sophisticated and closer to a meta-model ideal, the further away it becomes in relation to other areas and, worse still, further away it becomes from real and actual business practices, i.e. from what actually people do, how they act and think in current organisations. Seventh, the supply chain model and related approaches has had a huge effect at business level, improving operations and efficiency internally and has also been extended in order to affect world wide business relations through partnerships and alliances in a globalised and electronically connected world, but it unleashed a level of complexity in terms of geopolitical tensions and of the internal balance of national economies and of their financial structures that is unprecedented and that radically urges scientists, practitioners and policy makers to go beyond reductive and simplistic approaches that are dominant in mainstream thinking, both in management and in information sciences. Eight, the links between knowledge and power, which have been largely explored by post-modernist thinkers, and the crucial role of paradox, of conflict, of contradiction and of the discursive and narrative language mechanisms that are the hosts and 
vehicles of such power strains, together with the power links between academia, industry and politicians and the hidden tensions that condition their action, have been largely neglected, dismissed and ignored by mainstream managerial and information sciences, severely conditioning the creative, innovative, transformative and wealth creating power of knowledge. Ninth, the theoretical grounding of management and information sciences has systematically left to non-mainstream thinking those areas that do not fit the command and control management paradigm of the industrial era, thus ignoring complexity and change, and the pressures of faster and more efficient innovation, entrepreneurship and business initiative, that have been voiced in a consensual and unanimous manner by all leaders of society, from politicians to practitioners and intellectual gurus, ignore the idea of an ecosystem and the vast developments that have occurred in the chaos and complexity theory fields. Tenth, this array of nine issues that characterise current challenges for businesses and organisations radically calls for the use of the philosophical knowledge that has already been developed in the past and for the further development and integration of new perspectives, approaches and world-views, and semiotics offers a huge potential in this developmental process precisely because it is able to deal with operational and with strategic knowledge, with tangible and intangible processes, with micro, mezzo and macro levels, with individual, group, organisation and societal dimensions, with conscious, intentional and predetermined actions and with the prereflexive, spontaneous and creative processes that prefigure formal thought and action.

Further questions: - First: can philosophy or even semiotics be a panacea for the solution of all society's problems? No. But can a philosophical and a semiotic background help managers and information scientists and practitioners to improve and to optimise their current practices and theory building efforts? Yes.

- Second: can formal educational and professional training institutions reformulate their products in order to take into account knowledge that is not captive of an industrial society context and that radically prepares professionals to the already present context of post-industrial society? No. But can present educational systems incorporate the key insights and rationale of philosophically based thinking and action? Can semiotics, in particular, be accessible to lay people? Is it possible to create pos-graduate courses and doctoral and post-doctoral programmes that do not take semiotics as one more curricular entity or an optional discipline but that rather redesign present contents and structure in such a way that semiotics may be a practical and a hands-on methodology, a theoretical frame of reference and also a reading matrix and external view-point from which to analyse and constructively critique all action? Can semiotics be explained in a way that it becomes obvious how it may help businesses to improve their profitability, professionals to improve their performance, and work practices to be more gratifying and meaningful? Yes, to all these questions.

- Third: can present knowledge communities, and their counter parts in terms of the publishing industry and academic departments, closed onto their regional and local epistemic options and power relations, escape the limitations that have enabled them in the past to acquire their present positions, escape the locked-in effect of past success and openly explore new opportunities and challenges? No. But can these same communities, institutions, and businesses explore new venues of research and 
practice that help them to do better what they were already doing in the past, to go beyond what they were already doing, to integrate past approaches in broader, richer and more complex frameworks, more gratifying at professional and personal levels? Yes.

- Fourth: can political institutions recognise the potential they have in terms of spill-over effects, of their capacity to set the standards of best practices in exemplary ways? No. But is it possible to profit from the present consensus across industry, academia and the political spheres that knowledge is crucial in order to sustain competitiveness and long term survival, at business and at regional, national and transnational levels and to create hands-on approaches, not recipe like or one-fits-all models, but rather initiatives that have transformational power, that are grounded in both practice and theory and that enable actual change and improvement of current practices? Yes.

- Fifth: is there a top-down or bottom-up strategy, or a charismatic leader or expert commission, or a new ideology or utopia that may guarantee successful change, at individual, organisational or societal levels? No. But is it possible to act with rigour and to persevere in the process of working on the hinge of controversial issues, to openly contrast opposing positions, to clarify new possibilities, integrations and bridges across different disciplinary fields, different schools of thought and different power territories? Yes.

- Sixth: is it possible to bluntly solve businesses or world problems? No. But is it possible to advance in both practice and theory guaranteeing that there is a degree of openness and of inquiry capacity that enables that all possibilities of reality are actually manifest? Yes. And can semiotics be the engine and the Trojan horse of such changes? Yes.

As argues Stamper:

"Above all, information systems are the instruments we use for creating relationships between people, the communities in which we live, and the vast, evolving global social fabric. The problems of technically efficient computing remain interesting, but they are relatively minor compared with the other problems that we have hardly begun to address.... Or do we want to become the architects of the organisations and institutions in which we all live our post-industrial lives, enjoying with others greater openness, trust, fairness, justice but also greater individual self-realisation, power and responsibility? These are also qualities of information systems." (Stamper, 2000).

\section{Conclusions}

The present paper has addressed the current context of the post-industrial society and the challenges posed to businesses and organisations. The role of information technology has had a crucial impact in these societal changes, both as a product and producer of change, as a result and as an enabler of transitions that transverse all levels and domains of society. Semiotics plays a crucial role in terms of its potential to deal with widely diverse aspects of reality, addressing complexity, temporality and change.

This paper illustrates the efforts to incorporate semiotic theory in actual management practice through the example of Semiotic Learning, an organisational learning framework and practical method. The design of the Semiotic Learning framework addresses the problem of lack of support for informal 
learning and for knowledge creation and sharing at a tacit level. The question of how to improve organisational learning and, more specifically, the question of how to raise awareness towards the factors that are important in organisational learning is critical in this context. This is particularly relevant for knowledge-intensive organisations. Awareness towards the importance of the organisational community dimension and of social interaction is crucial because informal learning and sharing of tacit knowledge is only possible precisely through active participation in concrete organisational collective practices.

This paper also questioned current practices in academia, industry and policy-making spheres, arguing for the radical need for semiotic based educational approaches, enabling the application of semiotic theory as a powerful tool and methodology, unleashing businesses and organisational potential, and proving that it is possible to profit from semiotics' high return on investment at intra and inter-organisational levels.

\section{Bibliography}

